Revista PSICOLOGIA, 2014, Vol. 28 (2), 21-30

\title{
A Entrevista Cognitiva Melhorada: Pressupostos teóricos, investigação e aplicação
}

\author{
Rui M. Pauloํㅗㄹ Pedro B. Albuquerque ${ }^{1}$, Ray Bull ${ }^{2}$ \\ ${ }^{1}$ Escola de Psicologia, Universidade do Minho \\ ${ }^{2}$ Departamento de Psicologia, University of Portsmouth
}

\begin{abstract}
Resumo: A entrevista de testemunhas é um procedimento fundamental no decurso das investigações policiais e avaliações forenses. No entanto, o conhecimento, formação e treino destes profissionais para entrevistar testemunhas é frequentemente insuficiente, levando ao uso de técnicas de entrevista inadequadas e à obtenção de informação limitada e pouco fidedigna. Neste artigo abordamos a Entrevista Cognitiva Melhorada, atualmente aceite como um dos métodos mais eficazes para obter bons testemunhos. Descrevemos pormenorizadamente esta entrevista, quais os pressupostos teóricos que justificam a sua utilização, incidindo ainda sobre a investigação relevante. Por fim, elaboramos um guia de utilização para esta entrevista baseado nos resultados da investigação e no modelo utilizado pelas forças policiais de Inglaterra e Gales (i.e. "PEACE"). Não existindo nenhum outro protocolo publicado em língua portuguesa para a aplicação da Entrevista Cognitiva Melhorada, consideramos a leitura deste artigo um primeiro passo para todos os profissionais que pretendam utilizar este modelo de entrevista.
\end{abstract}

Palavras-chave: Entrevista Cognitiva Melhorada; Entrevista de Testemunhas; Investigação Policial; Avaliação Forense; Memória de Testemunhas.

The Enhanced Cognitive Interview: Theory, research and implementation: Interviewing witnesses is a fundamental procedure during police investigations and forensic evaluations. However, professionals" knowledge, training and experience to interview witnesses is often scant, leading to the use of improper interview techniques and the obtaining of limited and unreliable information. In this paper we address the Enhanced Cognitive Interview, currently accepted as one of the most effective methods to obtain good accounts. We fully describe this interview, the theoretical principles that justify its use, and the relevant research. Lastly, we have developed a Portuguese guide for using this interview, based on research and on the interviewing approach used by police forces in England and Wales (i.e. "PEACE"). Since no other protocol for the implementation of the Enhanced Cognitive Interview has been published in Portuguese, we consider reading this article a first step for all professionals that wish to use this style of interviewing.

Keywords: Enhanced Cognitive Interview; Witness Interviewing; Police Investigation; Forensic Evaluation; Witnesses Memory.

A entrevista de testemunhas determina frequentemente o sucesso de uma investigação policial ou avaliação forense (Milne \& Bull, 1999). No entanto, o relato das testemunhas raramente corresponde exatamente ao que aconteceu, ou até ao que as testemunhas memorizaram, pois diversos erros e omissões são cometidos durante o relato. 0 uso de técnicas de entrevista inadequadas, frequentemente utilizadas em contexto policial e forense (e.g., uso excessivo de questões), leva frequentemente à obtenção de fracos testemunhos (Paulo, Albuquerque, \& Bull, 2013).

Com o objetivo de criar um protocolo adequado para a entrevista de testemunhas que permitisse obter o máximo de informação correta possível, Geiselman e col. (1984) desenvolveram a Entrevista Cognitiva. Esta entrevista é atualmente aceite como um dos melhores métodos para obter bons testemunhos (Fisher \& Geiselman, 1992; Prescott, Milne, \& Clark, 2011). No entanto, entrevistar adequadamente uma testemunha é um procedimento extremamente difícil e exigente, particularmente quando são utilizados modelos de entrevista complexos como este (Griffiths, Milne, \& Cherryman, 2011).

Dados de contacto para correspondência: Rui M. Paulo, Escola de Psicologia, Universidade do Minho, Campus de Gualtar, 4710 - 057 Braga, Portugal. E-mail: id4299@alunos.uminho.pt.

Dado que um dos autores deste artigo exerce atualmente funções de diretor associado na PSICOLOGIA o processo de revisão do presente artigo foi tratado de forma independente pelo Diretor da revista que convidou académicos especialistas em memória humana, exteriores ao atual corpo editorial da revista, para proceder à revisão crítica do artigo.

Este trabalho foi financiado pela Fundação para a Ciência e a Tecnologia de Portugal (Referência: SFRH / BD / 84817/2012). 
Para tal, é fundamental que o entrevistador compreenda como, e quando, utilizar cada um dos procedimentos do protocolo de entrevista. Conhecer os pressupostos teóricos que fundamentam cada um dos procedimentos da Entrevista Cognitiva, os diversos protocolos de aplicação da mesma, e os resultados da investigação existente acerca deste tema, é essencial para este fim. Assim, ao longo do presente artigo, iremos descrever em pormenor a Entrevista Cognitiva e abordar os pressupostos teóricos inerentes a cada um dos seus procedimentos. Iremos também mostrar os resultados de investigações que aplicaram esta entrevista em diferentes contextos ou manipulando diferentes variáveis. Por fim, iremos analisar e descrever um modelo de aplicação desta entrevista, providenciando algumas diretrizes para a condução de uma boa entrevista forense/policial. Pretendemos assim criar um protocolo em língua portuguesa para a aplicação da Entrevista Cognitiva que permita entrevistar testemunhas de forma adequada.

\section{ENTREVISTA COGNITIVA (MELHORADA)}

Vários estudos mostraram que a Entrevista Cognitiva Melhorada permite obter mais informação por parte das testemunhas sem comprometer a exatidão dos seus relatos (Aschermann, Mantwill, \& Köhnken, 1991; Fisher \& Geiselman, 1992; Milne, Sharman, Powell, \& Mead, 2013). Este modelo de entrevista tem sido utilizado pelas forças policiais de diversos países (e.g., Inglaterra, Gales, Nova Zelândia). Mostrou também ser eficaz com diferentes testemunhas - e.g., crianças, adultos ou idosos (Verkampt \& Ginet, 2009; Wright \& Holliday, 2006), diferentes tipos de episódios a recordar - e.g., crimes, acidentes, gravações telefónicas (Campos \& Alonso-Quecuty, 2008) e diferentes intervalos de tempo entre o episódio a recordar e a entrevista - desde poucos minutos a várias semanas (Larsson, Granhag, \& Spjut, 2002), tanto em laboratório como em estudos realizados com testemunhas de crimes reais, entrevistadas pelas próprias forças policiais (Paulo et al., 2013).

Originalmente a Entrevista Cognitiva continha quatro mnemónicas: Relatar Tudo, Restabelecimento do Contexto, Mudança de Ordem e Mudança de Perspetiva.

A mnemónica Relatar Tudo consiste em pedir à testemunha que relate tudo o que recorda, com o maior grau de detalhe possível, mesmo que tal informação possa parecer trivial ou irrelevante à testemunha (Fisher \& Geiselman, 1992). Esta mnemónica é fundamental pois evita que as testemunhas omitam detalhes que consideram irrelevantes para a investigação. Embora, no dia a dia, os seres humanos estejam habituados a relatar episódios descrevendo apenas os acontecimentos centrais, até o mais pequeno detalhe pode ser decisivo para uma investigação policial. Adicionalmente, nem sempre a testemunha sabe avaliar qual a informação que poderá ser útil para a investigação. Por fim, os diversos traços de memória relativos a um acontecimento estão frequentemente associados (Tulving, 1991). Assim, a ativação de uma memória aparentemente irrelevante para a investigação, poderá ser pista para outras memórias extremamente relevantes. Por estas razões, pedir à testemunha que adote este estilo comunicativo, relatando todos os detalhes de que se recorda, é uma instrução fundamental.

A mnemónica Restabelecimento do Contexto consiste em pedir à testemunha que recrie mentalmente o contexto físico do crime, bem como o seu estado fisiológico, cognitivo e emocional durante o mesmo. Esta mnemónica é crucial, pois uma dada memória é mais facilmente recuperada quando é recriado o contexto em que esta foi codificada, ou seja, o contexto em que foi "memorizada" (Tulving \& Thomson, 1973). A utilização desta mnemónica é particularmente importante quando são entrevistadas crianças, pois a sua memória está fortemente associada ao contexto (Milne, 1997). Adicionalmente, embora alguns adultos utilizem esta mnemónica espontaneamente, as crianças são incapazes de o fazer (Gathercole \& Hitch, 1993).

A mnemónica Mudança de Ordem é executada pedindo à testemunha para relatar o crime através de uma ordem temporal diferente, habitualmente a ordem inversa. Pretende-se assim que a testemunha utilize uma estratégia de recuperação diferente, pois diferentes estratégias de recuperação poderão ativar diferentes memórias (Tulving, 1991). Esta mnemónica é particularmente útil quando a testemunha mantém um forte esquema mental (padrão organizado de pensamentos e comportamentos) sobre o tipo de evento que procura relatar (Griffiths \& Milne, 2010). Para compreendermos este conceito, imaginemos um segurança de um bar que todos os dias assiste a disputas entre os clientes. Este poderá ter um esquema mental marcado acerca do que é uma habitual "luta de bar": dois homens confrontam-se verbalmente, posteriormente recorrem à violência física através de murros e empurrões, sendo por fim expulsos do bar. Por esta razão, se questionado acerca de um destes episódios em particular, esta testemunha poderá exibir dificuldade em recordá-lo, evocando inadvertidamente memórias das restantes disputas. Poderá ainda omitir memórias que não sejam consistentes com o esquema mental que construiu. Por exemplo, poderá não relatar que um dos envolvidos utilizou técnicas de artes marciais, pois tal ato não é consistente com o esquema mental referido - uso de empurrões e murros. Uma vez que estes esquemas mentais são construídos e armazenados na nossa memória por ordem cronológica, 
recordar o crime numa ordem temporal diferente poderá evitar a interferência dos mesmos na recordação do acontecimento particular (Dando \& Milne, 2009).

Por fim, a mnemónica Mudança de Perspetiva consiste em pedir à testemunha para recordar o evento a partir de uma perspetiva diferente. Pode ser pedido à testemunha para adotar uma nova perspetiva externa (e.g.,"Conte-me agora tudo o que viu e que o funcionário do banco poderá também ter visto.") ou interna (e.g., "Sei que neste momento está um pouco nervosa. No entanto, tente adotar uma perspetiva mais relaxada tal como se sentia no dia do assalto antes de se aperceber que um crime estava prestes a ocorrer."). Tal como o procedimento anterior (Mudança de Ordem), esta mnemónica pretende que as testemunhas utilizem uma estratégia de recuperação diferente, facilitando a evocação de novos detalhes.

Alguns anos mais tarde, Fisher e Geiselman (1992) concluem que a utilização das quatro mnemónicas anteriormente propostas não conduz necessariamente à obtenção de um bom relato. Estes autores apercebem-se que os agentes policiais negligenciavam frequentemente procedimentos fundamentais para garantir o bem-estar psicológico e cooperação das testemunhas (e.g., estabelecer uma boa relação com a testemunha), diminuindo assim a qualidade do relato obtido. Por esta razão, adicionam ao protocolo da Entrevista Cognitiva um conjunto de componentes sociais e comunicativos cruciais para a realização de uma boa entrevista. Surge assim a Entrevista Cognitiva Melhorada.

0 primeiro procedimento adicionado baseia-se na construção de um relacionamento adequado com a testemunha (rapport building). Refere-se ao estabelecimento de uma relação adequada e positiva com a mesma. Este procedimento começa por ser realizado desde o primeiro momento em que o entrevistador contacta com a testemunha (e.g., por telefone) até ao último contacto que mantém com esta. Trata-se de um procedimento fundamental pois contribui para o bem-estar da testemunha durante a entrevista. A investigação acerca deste tema mostra que uma testemunha calma e segura é geralmente capaz de recordar mais detalhes do que uma testemunha nervosa ou desconfortável (Paulo et al., 2013).

0 segundo procedimento chama-se transferência do controlo da entrevista para a testemunha. Consiste em comunicar à testemunha que, durante a entrevista, ela é a única que está na posse da informação acerca do acontecimento e que, por isso, a pode relatar. Esta instrução é fundamental pois as testemunhas consideram frequentemente que o entrevistador irá apenas colocar questões acerca dos aspetos que pretende ver abordados, sustentando-se na informação que possui acerca do crime. No entanto, deve ser clarificado à testemunha que é ela quem detém a informação valiosa acerca do crime, e não o próprio entrevistador. Neste sentido, cumpre à testemunha esforçar-se para relatar o máximo de informação possível, e não apenas responder às questões do entrevistador. Deve igualmente ser comunicado à testemunha que esta detém completo controlo sobre o seu relato, por exemplo, podendo iniciar o relato livre pelo momento do crime que considerar mais pertinente. Esta instrução pretende responsabilizar a testemunha pelo seu próprio relato, maximizando o seu desempenho (Paulo et al., 2013).

O terceiro procedimento denomina-se questionamento compatível com a testemunha e consiste em colocar as questões certas no momento adequado. Ou seja, todas as questões devem ser compatíveis com o relato da testemunha e as estratégias de recuperação por esta utilizadas. Por exemplo, se a testemunha começa por descrever um assalto a um banco relatando a forma como o ladrão saiu do banco, o entrevistador não deve colocar questões sobre o momento em que o ladrão entrou no banco. Ou seja, o entrevistador não pode interferir negativamente com a estratégia de recuperação da testemunha, por exemplo, interrompendo-a. A utilização deste procedimento torna impossível estabelecer protocolos de entrevista padrão, pois cada entrevista terá de ser adaptada ao discurso da testemunha.

0 último procedimento, denominado de visualização mental, é semelhante à mnemónica de Restabelecimento do Contexto. No entanto, em vez de ser pedido à testemunha que recrie mentalmente o cenário global do crime, é pedido à testemunha para recriar mentalmente detalhes mais específicos "feche os olhos e pense na melhor imagem que tem da roupa que o ladrão vestia". Esta mnemónica deriva também da premissa de que uma memória é mais facilmente recuperada quando recriado o contexto em que esta foi codificada (Tulving \& Thomson, 1973).

Tal como referido, ao longo dos anos, vários investigadores têm estudado este modelo de entrevista. Geiselman, Fisher, MacKinnon, e Holland (1985) relatam que a Entrevista Cognitiva é particularmente eficaz quando o evento a ser recordado contém muita informação, tal como acontece na maioria dos crimes. Milne (1997) conclui que a Entrevista Cognitiva Melhorada é eficaz quando utilizada com grupos vulneráveis, por exemplo, crianças com problemas de aprendizagem. Alguns investigadores procuraram também avaliar a eficácia das diversas técnicas e mnemónicas que compõem esta entrevista. Por exemplo, Vredeveldt e Penrod (2013) avaliaram a importância de fechar os olhos durante a mnemónica de Restabelecimento do Contexto, concluindo que este procedimento contribui para a recuperação de mais informação. Holliday e Albon (2004) sugerem ainda que esta entrevista pode 
proteger a memória da testemunha contra a interferência de informação pós-evento enganosa (e.g., notícias televisivas acerca do crime). Memon, Zaragoza, Clifford e Kidd (2010) concluem que a aplicação da Entrevista Cognitiva Melhorada previamente a uma tentativa deliberada do entrevistador em implantar falsas memórias (Loftus \& Palmer, 1974), reduz o número de falsas memórias evocadas nas entrevistas posteriores.

Nas últimas décadas a Entrevista Cognitiva Melhorada tem sido o modelo predominantemente utilizado para a entrevista de testemunhas (Griffiths \& Milne, 2010). No entanto, a utilidade de alguns dos seus componentes e mnemónicas tem sido questionada (McMahon \& Greenwood, 2005). A mnemónica Mudança de Perspectiva e, num menor grau, Mudança de Ordem são frequentemente procedimentos morosos e difíceis de aplicar. A título de exemplo, algumas testemunhas parecem ser incapazes de colocar-se na perspectiva de uma outra testemunha para relatar o que recordam acerca de determinado crime. Adicionalmente, estas mnemónicas são por vezes pouco eficazes, ou seja, incapazes de provocar um aumento considerável no número de informação evocada pela testemunha (Bensi, Nori, Gambetti, \& Fiorella, 2011). Assim, alguns investigadores propõem a utilização de versões reduzidas desde modelo de entrevista, bem como mnemónicas e procedimentos alternativos com o objetivo de aumentar a eficácia da Entrevista Cognitiva Melhorada. McMahon e Greenwood (2005) sugerem retirar estas duas mnemónicas e/ou substitui-las por duas tentativas adicionais de recuperação (relatar novamente o episódio). Dando, Wilcock, Behnkle e Milne (2011) desenvolveram um procedimento alternativo para a aplicação da mnemónica de Restabelecimento do Contexto, através do uso de um esquema/desenho. Brunel, Py e Launay (2013) sugerem incluir uma segunda tentativa de recuperação antes da fase de questionamento. Em suma, ao longo das últimas décadas, vários investigadores têm-se focado neste modelo de entrevista, não só no sentido de explorar e avaliar os seus componentes, mas também de aumentar a sua eficácia e utilidade.

Com o objetivo de melhorar a compreensão do leitor em relação e este modelo de entrevista, abordámos os vários componentes da Entrevista Cognitiva Melhorada, a sua origem, e as teorias e investigações que sustentam a sua utilização. De seguida procuramos construir um guia em língua portuguesa para a aplicação da Entrevista Cognitiva Melhorada, com base na análise da investigação laboratorial e de campo nesta área, e considerando as directrizes apontadas por estes autores para a aplicação adequada deste modelo de entrevista. Baseámo-nos ainda no modelo PEACE (Planning and preparation; Engage and explain; Account; Closure; Evaluation) que é o protocolo utilizado em Inglaterra e Gales para entrevistar testemunhas cooperantes (Griffiths \& Milne, 2010). Não obstante, tal como iremos debater no final do artigo, este modelo poderá necessitar de adaptações específicas ao funcionamento interno das diversas forças policiais ou de cada instituição que pretende aplicar este modelo de entrevista (e.g., unidades de avaliação forense).

\section{APLICAÇÃO DA ENTREVISTA COGNITIVA MELHORADA}

Como já referimos, a Entrevista Cognitiva Melhorada é utilizada por inúmeras forças policiais, e outros profissionais, um pouco por todo o Mundo. No entanto, apenas em alguns países (e.g., Inglaterra, Gales, Nova Zelândia) existem diretrizes claras para a utilização desta entrevista. De facto, Inglaterra é talvez o melhor exemplo de um país onde esta entrevista foi adaptada e incluída nos protocolos das forças policiais como método principal para a entrevista de testemunhas (Griffiths \& Milne, 2010). Neste país existem ainda inúmeras investigações que avaliam a eficácia deste modelo de entrevista em casos reais, bem como as perceções dos agentes policiais em relação à aplicação deste modelo (Wheatcroft, Wagstaff, \& Russell, 2013). Investigações acerca da avaliação do desempenho dos agentes policiais no que diz respeito à aplicação da Entrevista Cognitiva Melhorada, ou acerca da eficácia dos extensos programas de treino a que os agentes policiais são sujeitos, são também abundantes neste país (Griffiths, Milne, \& Cherryman, 2011). Por estas razões, iremo-nos focar no modelo PEACE que, tal como referido, se trata do protocolo utilizado em Inglaterra e Gales para entrevistar testemunhas cooperantes (Griffiths \& Milne, 2010). Este modelo de entrevista, baseado na Entrevista Cognitiva Melhorada, foi extensivamente investigado e avaliado por investigadores e agentes policiais (Milne, Shaw, \& Bull, 2007). Ao longo dos próximos parágrafos iremos também fornecer algumas indicações para a aplicação da Entrevista Cognitiva Melhorada, provenientes da investigação existente acerca deste tema. No Quadro 1 podemos observar um esquema da estrutura de aplicação da Entrevista Cognitiva Melhorada que iremos analisar de seguida.

0 modelo esquematizado é apenas um modelo ilustrativo no sentido em que algumas das fases (e.g., fase 6 - Questões importantes para a investigação) e procedimentos descritos (e.g., foco em vários sentidos) poderão, em determinadas ocasiões, ser aplicados por ordens diversas ou mesmo não ser utilizados. Embora no contexto empírico, por questões de controlo experimental, sejam usualmente aplicados todos os componentes da Entrevista Cognitiva Melhorada utilizando uma ordem de aplicação 
padronizada, a capacidade do entrevistador em flexibilizar estes procedimentos no contexto profissional é imprescindível para o uso adequado de qualquer entrevista investigativa (Fisher \& Geiselman, 1992). Da mesma forma, embora algumas mnemónicas da Entrevista Cognitiva Melhorada devam ser utilizadas em todas as entrevistas (e.g., Contar Tudo), outros procedimentos poderão ser inadequados para determinada investigação (e.g., Mudança de Perspetiva ou Mudança de Ordem). Assim, as diversas fases, procedimentos e mnemónicas devem ser conceptualizadas como uma "caixa de ferramentas". Quer isto dizer que cabe ao entrevistador escolher as técnicas que melhor se adequam a cada investigação, flexibilizando e adequando a entrevista.

Quadro 1. Aplicação da Entrevista Cognitiva Melhorada de acordo com o modelo "PEACE”.

\begin{tabular}{|c|c|c|c|c|c|}
\hline \multirow{3}{*}{\multicolumn{2}{|c|}{ Fase 1}} & & & & \\
\hline & & & & a) & Cumprimentar \\
\hline & & & & b) & Personalizar a entrevista \\
\hline \multirow{4}{*}{\multicolumn{2}{|c|}{ Fase 2}} & & & & \\
\hline & & & & a) & Solicitar concentração da testemunha \\
\hline & & & & b) & Contar Tudo \\
\hline & & & & c) & Transferir controlo \\
\hline \multirow{5}{*}{\multicolumn{2}{|c|}{ Fase 3}} & & & Relato livre & \\
\hline & & & & a) & Restabelecimento do Contexto \\
\hline & & & & b) & Questões de resposta aberta \\
\hline & & & & c) & Pausas \\
\hline & & & & d) & Não interromper a testemunha \\
\hline \multirow{6}{*}{\multicolumn{2}{|c|}{ Fase 4}} & & & Questionamento & \\
\hline & & & & a) & Contar Tudo \\
\hline & & & & b) & Questões compatíveis com o discurso da testemunha \\
\hline & & & & c) & É normal "não recordar" \\
\hline & & & & d) & Visualização mental \\
\hline & & & & e) & Questões de resposta aberta \\
\hline \multirow{4}{*}{\multicolumn{2}{|c|}{ Fase 5}} & & & & \\
\hline & & & & a) & Mudança de Ordem \\
\hline & & & & b) & Mudança de Perspetiva \\
\hline & & & & c) & Foco em vários sentidos \\
\hline & \multicolumn{4}{|c|}{ Questões importantes para a investigação } & \\
\hline & \multicolumn{4}{|c|}{ Resumo } & \\
\hline & \multicolumn{4}{|c|}{ Encerramento } & \\
\hline & \multicolumn{4}{|c|}{ Avaliação } & \\
\hline
\end{tabular}

Fase 1 - Estabelecer uma boa relação com a testemunha

Estabelecer e manter uma boa relação com a testemunha é um procedimento fundamental não só no inicio, mas também ao longo de toda a entrevista. Desde o primeiro contacto com a testemunha, o entrevistador deve considerar este objetivo. Para tal, é fundamental que este cumprimente a testemunha e clarifique quem é e qual a instituição que representa, evitando manter uma postura autoritária e mostrando-se disponível para prestar o apoio necessário à testemunha. Este deve optar por não utilizar termos referentes à sua posição hierárquica na instituição (e.g., Superintendente). 0 entrevistador deve ainda clarificar qual o papel da testemunha na investigação, bem como a razão pela qual esta foi chamada para a entrevista. Deve ainda personalizar a entrevista, incluindo diversas vezes o nome da testemunha no seu discurso, e atendendo às necessidades e características particulares da mesma (Paulo et al., 2013). A título de exemplo, entrevistar uma testemunha com dificuldades comunicativas exige a adoção de um estilo comunicativo específico.

Nesta fase inicial da entrevista, o entrevistador deve abordar tópicos neutros com a testemunha. Através desta conversação inicial, o entrevistador procura não só que a testemunha se sinta confortável com a sua presença e o com o contexto da entrevista, mas também que a testemunha se habitue ao estilo de conversação utilizado. Para tal, assim como ao longo da entrevista, o entrevistador deve colocar maioritariamente questões de resposta aberta (e.g., “Como foi o seu dia?"). Deve igualmente procurar obter respostas detalhadas por parte do entrevistado, por exemplo, introduzindo silêncios para que este sinta necessidade de elaborar respostas mais longas.

\section{Fase 2 - Explicar os objetivos da entrevista}

Nesta fase, o entrevistador deve comunicar de forma clara e precisa o que irá acontecer ao longo de toda a entrevista. Transferir o controlo da entrevista para a testemunha é também um objetivo fundamental para esta fase da entrevista. Para tal, o entrevistador poderá basear-se na seguinte descrição:

"Embora neste momento esteja a ser eu quem mais intervém nesta entrevista, vou parar de o fazer dentro de momentos, pois foi você quem viu o crime e quem tem toda a 
informação importante. Não irei interrompê-la(o) e peço-lhe que me conte tudo o que se lembra acerca do crime, pela ordem que desejar. Pode fazer pausas sempre que quiser e podemos até parar alguns minutos, pois esta é uma tarefa que exige um grande esforço da sua parte."

É também neste momento que o entrevistador aplica a mnemónica Relatar Tudo, focando alguns pontos essenciais:

“Gostava que me contasse tudo o que se lembra acerca do crime, com o máximo de detalhe possível. Por favor, conte-me tudo de que se recorda, mesmo os detalhes que lhe possam parecer irrelevantes ou que apenas recorde parcialmente. Algumas pessoas omitem detalhes pois pensam que não são importantes. No entanto, eu estou interessado em tudo o que lhe vier à cabeça. Até o mais pequeno detalhe pode ser muito importante."

Por fim, para a implementação desta mnemónica, o entrevistador poderá ainda utilizar um exemplo para demonstrar o nível de detalhe que pretende obter. Por exemplo, poderá descrever exaustivamente uma garrafa de água para que a testemunha perceba que este está interessado em todo o tipo de detalhes, e não apenas numa descrição genérica da garrafa, e posteriormente do crime.

\section{Fase 3 - Relato livre}

O objetivo do entrevistador para esta fase é o de obter o melhor relato livre possível. É através do relato livre que a testemunha vai providenciar grande parte da informação acerca do crime pois, tal como iremos abordar de seguida, é esta a fase em que o entrevistador menos intervém no relato da testemunha. Assim, a informação obtida está menos sujeita a distorções ou erros, pois as questões que irão ser colocadas pelo entrevistador em fases posteriores podem influenciar a memória do entrevistado. Como iremos também abordar mais à frente, basta o entrevistador cometer um pequeno erro durante a fase de questionamento (e.g., colocar uma questão sugestiva - "O assaltante tinha luvas, não tinha?") para colocar em risco a exatidão do discurso da testemunha.

Para obter o melhor relato possível, o entrevistador deve utilizar a mnemónica Restabelecimento do Contexto:

"Peço-lhe agora que feche os olhos e os mantenha fechados durante todo o exercício, pois fechar os olhos ajuda a que obtenha uma imagem mais clara da cena do crime na sua mente. Pense no dia em que observou o crime...; pense no que estava a fazer nesse dia...; como se estava a sentir quando se dirigia para o local do crime...; agora imagine o cenário do crime e tente obter uma imagem clara..., muito clara..., desse cenário na sua mente...; pense agora em todos os objetos que estavam nesse cenário...; pense nos sons e vozes que se lembra ouvir...; pense nas pessoas que estavam presentes na cena do crime...; e agora foque-se no que aconteceu. Quando estiver pronto e tiver uma imagem clara do cenário do crime na sua mente, mantendo os olhos fechados e usando todo o tempo que precisar, diga-me tudo o que se lembra pela ordem que quiser e estabelecendo as pausas que desejar."

Esta instrução deve ser comunicada de forma pausada, dando tempo à testemunha para recriar o contexto do crime na sua mente. Deve também ser mantido um tom de voz com volume reduzido pois um volume elevado pode interferir com a tentativa da testemunha em recriar o contexto do crime. Tal como referido, durante o relato livre o entrevistador deve interromper o menos possível a testemunha, de forma a não interferir com o seu relato, bem como com as estratégias de recuperação utilizadas pela testemunha. Caso seja necessário, algumas questões de resposta aberta podem ser utilizadas para direcionar o discurso da testemunha. Não obstante, o entrevistador deve ter particular cuidado com o tipo de questões que coloca. Por exemplo, caso o entrevistador introduza nova informação nas suas perguntas (e.g., referir a arma do crime antes da testemunha narrar a sua existência), a memória da testemunha poderá sofrer distorções. Sempre que necessário devem ser estabelecidas pausas. Caso a testemunha não se sinta confortável para fechar os olhos, deve ser instruída para olhar para um local fixo da sala (e.g., um ponto fixo de uma parede), evitando assim distrações que dificultem o restabelecimento do contexto.

\section{Fase 4 - Questionamento}

Após obter um relato livre extenso e completo, o entrevistador poderá colocar algumas questões baseadas no discurso da testemunha. Nesta fase, o entrevistador deve recordar à testemunha para relatar 
tudo o que se lembra, mesmo os detalhes que pareçam ser irrelevantes. Deve ainda comunicar à mesma que esta deverá responder que não se recorda sempre que seja esse o caso e que esta é uma resposta tão valiosa como outra qualquer. Esta instrução é particularmente importante com crianças pois estas tendem a dar respostas sobre as quais não estão certas, com o intuito de não dececionar o entrevistador. Como já referido, as questões colocadas devem ser sempre compatíveis com o discurso da testemunha. Por exemplo, se a testemunha está a descrever o assaltante, o entrevistador deve colocar todas as questões que tem acerca deste aspeto, antes de a questionar sobre o tópico seguinte. Na fase de questionamento, o entrevistador poderá também utilizar a técnica de Visualização Mental:

\begin{abstract}
"Disse-me que, quando o assaltante entrou no banco, olhou fixamente para ele pois este parecia um pouco agitado. Peço-lhe agora que feche os olhos e recrie a imagem que tem do assaltante quando este entrou no banco. Foque-se em todos os pormenores que se lembra acerca do mesmo: o seu vestuário...; a sua expressão facial ...; o seu cabelo ...; os seus olhos ...; [etc.]. Quando tiver uma boa imagem mental do assaltante, conte-me tudo o que se lembra acerca dele."
\end{abstract}

Por fim, o entrevistador deve utilizar maioritariamente questões de resposta aberta ao longo de toda a entrevista ("O que fez o assaltante quando saiu do banco?"). Como referimos anteriormente, questões de resposta fechada ("O assaltante tinha luvas?"), escolha múltipla ("O assaltante tinha uma máscara ou um chapéu?") ou sugestivas ("O assaltante tinha luvas, não tinha?") conduzem a respostas pouco informativas e aumentam o número de erros cometidos pela testemunha, pelo que devem ser evitadas.

\title{
Fase 5 - Novas estratégias de recuperação
}

Como referido, o protocolo de aplicação da Entrevista Cognitiva Melhorada deve ser flexível e adequado às características da testemunha, do episódio em causa e do tipo de informação que o entrevistador pretende obter. Nesta fase, a capacidade do entrevistador em adaptar a entrevista é particularmente importante, pois as técnicas que iremos abordar poderão ser aplicadas de diferentes formas ou até não ser aplicadas de todo. Caso seja claro para o entrevistador que a testemunha já relatou exaustivamente tudo o que recorda acerca do crime, utilizar novas estratégias de recuperação poderá ser ineficaz. No entanto, caso o entrevistador considere que a testemunha poderá ainda ser capaz de relatar mais informação, através do uso de novas estratégias de recuperação, algumas estratégias poderão ser utilizadas.

Uma destas estratégias é a utilização da mnemónica Mudança de Ordem. Ao aplicar esta mnemónica o entrevistador deverá instruir a testemunha da seguinte forma:

“Agora gostaria que fizéssemos outra tarefa que, por vezes, ajuda as pessoas a lembrarem-se de ainda mais informação. Gostava que me contasse novamente tudo o que se lembra acerca do crime, mas, desta vez, pela ordem inversa. Ou seja, comece por relatar o último acontecimento que se lembra, e depois passe para o que aconteceu imediatamente antes disso, e por aí fora. Sei que parece difícil mas irei ajudá-la(o). Qual foi o último acontecimento de que se lembra?"

Caso o entrevistador opte por utilizar esta mnemónica, deve auxiliar a testemunha ao longo de todo o processo. Após a testemunha descrever tudo o que se lembra acerca de determinado momento do crime, o entrevistador deverá pedir à mesma que descreva o episódio que ocorreu imediatamente antes.

A mnemónica de Mudança de Perspetiva pode também ser útil em algumas situações. Por exemplo, caso a testemunha tenha mostrado dificuldade em descrever as ações do assaltante, poderá agora ser-lhe pedido que relate novamente o crime, tal como se o assaltante fosse a personagem principal de uma peça de teatro:

"Queria agora pedir-lhe que relate o episódio a partir de uma perspetiva diferente, pois este procedimento ajuda as pessoas a relatar mais informação que previamente podem não ter recordado. Imagine que o assaltante, durante toda a cena do crime, se encontra sob um holofote, tal como uma personagem principal numa peça de teatro. Pedia-lhe que relatasse novamente tudo o que se lembra, tentando sempre focar-se no assaltante como se este fosse a personagem principal deste episódio." 
0 entrevistador pode ainda pedir à testemunha que relate novamente tudo o que se lembra acerca do crime, focando-se num sentido percetivo diferente. Tal procedimento pode também ser incluído numa das duas mnemónicas anteriormente descritas, por exemplo, pedindo à testemunha que relate o episódio pela ordem inversa, focando-se apenas no que se lembra de ouvir. Maioritariamente, as testemunhas focam-se na informação visual que têm do crime. Assim, pedir à testemunha que se foque num outro sentido percetivo poderá auxiliá-la a relatar nova informação. Adicionalmente, vítimas de alguns crimes (e.g., crimes sexuais) descrevem frequentemente ter fechado os olhos durante o momento do crime. Por esta razão, pedir a estas testemunhas que relatem o que ouviram/cheiraram/sentiram poderá ser extremamente vantajoso.

\section{Fase 6 - Questões importantes para a investigação}

Até esta fase da entrevista, a testemunha não deve ser questionada acerca de aspetos que não mencionou, por exemplo, questionada acerca da arma do crime sem esta ter narrado a sua existência. Este tipo de questões apresentam um caráter sugestivo, ou seja, poderão levar a testemunha a afirmar algo que não se recorda mas assume através do discurso do entrevistador. No entanto, em algumas investigações, poderá ser imprescindível colocar questões acerca de tópicos que a testemunha não mencionou durante a entrevista. Uma vez que, nesta fase da entrevista, todas as outras técnicas de questionamento foram já utilizadas e grande parte do relato da testemunha foi já obtido, o entrevistador poderá introduzir este tipo de questões, caso sejam imprescindíveis para a sua investigação. No entanto, o entrevistador deve estar ciente que a informação obtida através deste tipo de questões tem uma maior probabilidade de conter distorções ou erros (Fisher \& Geiselman, 1992). Mais uma vez, questões sugestivas, de resposta fechada ou escolha múltipla devem ser evitadas.

\section{Fase 7 - Resumo}

Chegado este momento, o entrevistador poderá sintetizar alguns pontos centrais do relato da testemunha, dando-lhe a oportunidade de acrescentar nova informação e/ou corrigi-la. Esta fase é opcional pois caso existam gravações vídeo da entrevista, o entrevistador terá a oportunidade de rever a gravação e esclarecer alguma dúvida que tenha em relação ao discurso da testemunha através dessa mesma gravação.

\section{Fase 8 - Encerramento}

Na fase de encerramento o entrevistador deverá novamente abordar tópicos neutros com a testemunha, tal como no início da entrevista. Ao longo da entrevista, a testemunha poderá ter abordado tópicos sensíveis e perturbadores. Assim, o entrevistador deve certificar-se de que a testemunha sai do local da entrevista sentindo-se calma e segura. É igualmente importante agradecer à testemunha pelo seu trabalho árduo ao longo de toda a entrevista. Desta forma, o entrevistador promove a colaboração da testemunha em futuras ocasiões, caso seja necessário. Para tal, este deve ainda fornecer um contacto à testemunha e informá-la de que poderá comunicar caso tenha alguma dúvida ou se recorde de algum outro detalhe.

\section{Fase 9 - Avaliação}

Após o término da entrevista, é importante avaliar o valor da informação obtida e o impacto que esta informação tem na investigação policial/ avaliação forense. É igualmente importante que o próprio entrevistador, ou o seu supervisor, avaliem o seu desempenho. 0 treino e avaliação são imprescindíveis para que qualquer entrevistador possa melhorar o seu desempenho em entrevistas posteriores (Griffiths \& Milne, 2010).

\section{CONCLUSÃo}

A Entrevista Cognitiva Melhorada é uma das técnicas mais eficazes para obter bons testemunhos, tendo sido alvo de imensas investigações e modificações ao longo das últimas décadas (Paulo et al., 2013). No entanto, é necessário conhecer a sua origem, os seus pressupostos teóricos, os protocolos de aplicação existentes e a investigação acerca deste tema, para utilizar eficazmente este modelo de entrevista. Com este artigo procurámos construir o primeiro protocolo em língua portuguesa para a aplicação da Entrevista Cognitiva Melhorada. No protocolo apresentado, dividimos a estrutura da entrevista em nove fases, explicando em que consistem, quais as técnicas a utilizar em cada uma destas fases, bem como a forma adequada de aplicar tais técnicas. Consideramos que a leitura deste artigo será um primeiro passo essencial para todos os profissionais que pretendam utilizar este modelo de entrevista.

Embora as mnemónicas e técnicas da Entrevista Cognitiva Melhorada possam já ser utilizadas por algumas forças policiais e unidades de avaliação forense portuguesas, o estatuto de reserva de divulgação 
de tais protocolos por esses profissionais impossibilitam o acesso e avaliação dos mesmos. A utilização adequada da Entrevista Cognitiva Melhorada obriga ainda a que as instituições disponham não só de programas de treino, mas também avaliação do desempenho dos entrevistadores (Poyser \& Milne, 2011). Por várias razões (e.g., formação insuficiente das próprias equipas de treino; falta de financiamento; reduzida cooperação por parte dos entrevistadores; etc.), não é esta a realidade portuguesa. Embora a Entrevista Cognitiva Melhorada seja o modelo de entrevista para testemunhas mais utilizado, e investigado, um pouco por todo o Mundo, em Portugal, são muito escassas as publicações, programas de treino e investigações acerca deste tema. De facto, para além da investigação que está a ser desenvolvida por Paulo, Albuquerque \& Bull (2014), não parece existir qualquer outro tipo de investigação em Portugal acerca da utilização da Entrevista Cognitiva Melhorada.

Por fim, destacamos que, embora o protocolo descrito ao longo deste artigo considere adaptações específicas ao funcionamento e protocolos das forças policiais em geral (e.g., condução da fase de resumo quando as instalações não permitem a gravação vídeo do depoimento), futuras colaborações com as diversas forças policiais portuguesas são imprescindíveis de forma a criar protocolos mais exclusivos da Entrevista Cognitiva Melhorada, maximizando a sua utilidade face à realidade policial portuguesa. A falta de articulação entre as várias instituições (e.g., forças policiais e equipas de investigação) dificulta que este tipo de investigação seja realizado.

\section{Referências}

Aschermann, E., Mantwill, M., \& Köhnken, G. (1991). An independent replication of the effectiveness of the cognitive interview. Applied Cognitive Psychology, 5, 489-495.

Brunel, M., Py, J., \& Launay, C. (2013). Cost and benefit of a new instruction for the cognitive interview: The open depth instruction. Psychology, Crime \& Law, 19, 845-863.

Campos, L., \& Alonso-Quecuty, M. (2008). Language crimes and the cognitive interview: testing its efficacy in retrieving a conversational event. Applied Cognitive Psychology, 22, 1211-1227

Dando, C., \& Milne, R. (2009). The cognitive interview. In R. Kocsis (Ed.), Applied criminal psychology: A guide to forensic behavioural sciences (pp. 147-169). Sydney, NSW: Charles C. Thomas.

Dando, C., Wilcock, R., Behnkle, C., \& Milne, R. (2011). Modifying the cognitive interview: Countenancing forensic application by enhancing practicability. Psychology, Crime \& Law, 17, 491-511.

Fisher, R. P., \& Geiselman, R. E. (1992). Memory-enhancing techniques for investigative interviewing: The cognitive interview. Springfield, IL: Charles C. Thomas.

Gathercole, S. E., \& Hitch, G. J. (1993). Developmental changes in short-term memory: A revised working memory perspective. In A. Collins, S. E. Gathercole, M. A. Conway, \& P. E. Morris (Eds.), Theories of memory (pp. 189-209). Hove, UK: Erlbaum.

Geiselman, R. E., Fisher, R. P., Firstenberg, I., Hutton, L., Sullivan, S. J., Avetissian, I. V., \& Prosk, A. L. (1984). Enhancement of eyewitness memory: An empirical evaluation of the cognitive interview. Journal of Police and Science Administration, 12, 74-80.

Geiselman, R. E., Fisher, R. P., MacKinnon, D. P., \& Holland, H. L. (1985). Eyewitness memory enhancement in the police interview: Cognitive retrieval mnemonics versus hypnosis. Journal of Applied Psychology, 70, 401-412.

Griffiths, A., \& Milne, R. (2010). The application of cognitive interview techniques as part of an investigation. In C. A. Ireland \& J. M. Fisher (Eds.), Consultancy and advising in forensic practice: Empirical and practical guidelines (pp. 71-90). Chichester, UK: BPS Blackwell.

Griffiths, A., Milne, R., \& Cherryman, J. (2011) A question of control? The formulation of suspect and witness interview question strategies by advanced interviewers. International Journal of Police Science \& Management, 13, 255-267.

Holliday, R., \& Albon, A. (2004). Minimising misinformation effects in young children with cognitive interview mnemonics. Applied Cognitive Psychology, 18, 263-281.

Davis, M., McMahon, M., \& Greenwood, K. (2005). The efficacy of mnemonic components of the cognitive interview: towards a shortened variant for time-critical investigations. Applied Cognitive Psychology, 19, 75-93.

Milne, R. J. (1997). Analysis and application of the cognitive interview. (Unpublished doctoral dissertation). University of Portsmouth.

Milne, R., \& Bull, R. (1999). Investigative Interviewing: Psychology and Practice. Chichester, WS :Wiley.

Milne, R., Sharman, S. J., Powell, M. B., \& Mead, S. (2013). Assessing the effectiveness of the cognitive interview for children with severe intellectual disabilities. International Journal of Disability, Development and Education, 60, 18-29. 
Milne, R., Shaw, G., \& Bull, R. (2007). Investigative interviewing: The role of psychology. In D. Carson, R. Milne, F. Pakes, and K. Shalev, (Eds.), Applying psychology to criminal justice (pp. 65-80). Chichester, UK: BPS Blackwell.

Larsson, A. S., Granhag, P. A., \& Spjut, E. (2002). Children's recall and the cognitive interview: do the positive effects hold over time? Applied Cognitive Psychology, 17, 203-214.

Loftus, E. F. \& Palmer, J. C. (1974). Reconstruction of automobile destruction: An example of the interaction between language and memory. Journal of Verbal Learning and Verbal Behavior, 13, 585-590.

Memon, A., Zaragoza, M., Clifford, B. R., \& Kidd, L. (2010). Inoculation or antidote? The effects of cognitive interview timing on false memory for forcibly fabricated events. Law and Human Behavior, 34, 105117.

Paulo, R. M., Albuquerque, P. B., \& Bull, R. (2013). The enhanced cognitive interview: Towards a better use and understanding of this procedure. International Journal of Police Science \& Management, 15, 190-199.

Paulo, R. M., Albuquerque, P. B. \& Bull, R. (2014). The Enhanced Cognitive Interview: Witnesses' certainty, motivation and perceptions towards the interviewer. Manuscrito submetidopara publicação.

Poyser, S., \& Milne, R. (2011). Miscarriages of justice: A call for continued research focusing on reforming the investigative process. The British Journal of Forensic Practice, 2, 61-71.

Prescott, K., Milne, R., Clark, J. (2011). How effective is the enhanced cognitive interview when aiding recall retrieval of older adults including memory for conversation. Journal of Investigative Psychology and Offender Profiling, 8, 257-270.

Tulving, E., \& Thomson, D. (1973). Encoding specificity and retrieval processes in episodic memory. Psychological Review, 80, 352-373.

Tulving, E. (1991). Concepts of human memory. In L. R Squire, N. M. Weinberger, G. Lynch, and J. L. McGaugh, (Eds.), Memory: Organization and locus of change (pp. 3-32). New York, NY: Oxford University Press.

Verkampt, F., \& Ginet, M. (2009). Variations of the cognitive interview: which one is the most effective in enhancing children's testimonies? Applied Cognitive Psychology, 24, 1279-1296.

Vredeveldt, A., \& Penrod, S. D. (2013). Eye-closure improves memory for a witnessed event under naturalistic conditions. Psychology, Crime \& Law, 19, 893-905.

Wheatcroft, J. M., Wagstaff, G. F., \& Russell, K. (2013). Specialist police interviewer perceptions of the enhanced cognitive interview: Usefulness, confidence and witness reliability. Police Practice and Research, 13, 1-14.

Wright, A., \& Holliday, R. (2006). Enhancing the recall of young, young-old and old-old adults with cognitive interviews. Applied Cognitive Psychology, 21, 19-43.

$\begin{array}{ll}\text { Historial do } & \text { artigo } \\ \text { Recebido } & 18 / 07 / 2014 \\ \text { Aceite } & 24 / 10 / 2014 \\ \text { Publicado } & 12 / 2014\end{array}$

